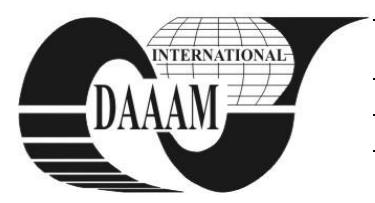

Annals of DAAAM for 2012 \& Proceedings of the 23rd International DAAAM Symposium, Volume 23, No.1, ISSN 2304-1382 ISBN 978-3-901509-91-9, CDROM version, Ed. B. Katalinic, Published by DAAAM International, Vienna, Austria, EU, 2012 Make Harmony between Technology and Nature, and Your Mind will Fly Free as a Bird Annals \& Proceedings of DAAAM International 2012

\title{
A COMPARATIVE ANALYSIS OF ORTHOPEDIC MEASURING METHODS
}

\author{
GUICA, R[aluca] I[oana]; TRIFAN, L[aura] \& MICU, A[nton] C[onstantin]
}

\begin{abstract}
Leg length inequality affects $65-70 \%$ of the population, therefore it is very important to use the appropriate methods for evaluating and measuring the discrepancies. This paper aims to analyze the existing measuring methods used by medical doctors in orthopedics and a new length measurement system, which belongs to the authors, highlighting the advantages and disadvantages of each method. A comparative analysis is described in order to assist the end-users in choosing the optimal measuring method for each patient, thus increasing the quality of life.
\end{abstract}

Keywords: measuring methods in orthopedy, leg length discrepancy, tests and measurements

\section{INTRODUCTION}

Leg length discrepancy refers to a condition characterized by the fact that the lower limbs are significantly unequal. According to Reid and Smith, there are three categories of inequality based on the disparity magnitude: mild (difference $<30 \quad \mathrm{~mm}$ ), moderate (differences are between 30 and $60 \mathrm{~mm}$ ), and severe (differences> $60 \mathrm{~mm}$ ) [29]. Therefore, it is important that the measurements will be performed using valid methods, that are reliable in terms of inter- and intra examination. Nowadays there are many measuring methods that evaluate the degree of inequality in the lower limbs, but none of them is universally accepted. In this paper the authors aim to compare the existing measurement methods, highlighting both advantages and disadvantages of each of them, and to analyse the methods based on five criteria, such as: accuracy, radiation level, price, availability and user related learning curve. It is important to choose the appropriate method for estimating the leg length discrepancy, in order to be able to make the right decision regarding the patient's treatment. [7]

The novelty of this research lies in the innovative approach regarding the technical solutions in determining the distance and geometric path between two points in space, applied to the landmarks of the human body. Thus, the modeling of a new measurement system was based on finding a solution that combines the best advantages of the existing methods and the requirements of the medical staff team. In the end, a device was obtained that does not expose the patient to radiation, is easy to use and can be attached directly to the patient's bed. In this way it is not longer necessary for the patient to be moved, thus increasing his comfort and quality of life. Also, to obtain an optimal level of financial performance, the acquisition and operating costs are aimed to be considerably lower than in currently used devices with comparable precison.

The limitations of this method refer to the fact that this measuring device is still at the design stage. We designed it in CATIA and for now undergoes various tests, so that at the end of this stage the optimal solution will be built. Another limitation is due to the fact that discussions were held with a relative small number of medical doctors and thus it only represent their own view regarding the solution to the problem - measuring limb discrepancyes.

For the time being, further testing is aimed, and for that the medical team will use a prototype to check if any changes should take place, before a mass production will be taken into consideration. Any suggestion or complaint will be taken into account, analyzed and, if feasible, implemented.

\section{THE ANALYSIS OF ORTHOPEDIC MEASURING METHODS}

Current clinical methods, that are used to assess the lower limb discrepancy include the following: measurement of the distance between two bone landmarks using a ruller-tape, wooden blocks or directly measuring pelvic crest height difference. Unfortunately doctors can rarely prescribe treatment based only on these assessments.

According to a number of studies $[10,6,26]$, the measurement method using a tape is commonly used, but subject to errors [5]. The results of the study by Beattie et al, show that the measured inequalities using a tape are valid only if two measurements are made for the same patient. However, it has also demonstrated that the results are less relevant when comparing leg lengths of healthy patients.

Also, the results obtained from these measurements do not define the degree of functional impairment caused by the leg length discrepancy.

The advantage of the measurement method using wooden blocks, is that the measurement is focused on the foot functionality, not only on its length. A disadvantage of this method is given by the ease with which the measurements are influenced by flexion, hip abduction and adduction [26, 32]. An alternative method is presented in Hanada's study [13] and involves the correction of the inequality with a book placed under the 
patient's shorter leg that is opened at the desired place in order to make a fine-adjustment. The method was tested on a group of 34 people, and the results show that the average difference between two measurements was from 1.6 to $2.5 \mathrm{~mm}$. Compared with the measurement method using wooden blocks, this one offers a greater accuracy because differences of 1 to $5 \mathrm{~mm}$ can also be measured, and the availability of books in a cabinet is greater than of wooden blocks. In conclusion this technique was proved to be reliable, when there is a history of pelvic deformity and the iliac crest can be easily palpated.

A very useful tool for measuring pelvic crest height difference is the PALM device (PALpation Meter) [20].

In one of their studys, Hagins and his colleagues [12] reported an inter-observer precision of 0.65 in the frontal plane and 0.89 in the sagittal plane and an intra-observer precision of 0.84 in the frontal plane and 0.98 in the sagittal plane. Also Petrone et all [27], demonstrated that the measurement device is excellent for determining pelvic crest height, but less accurate for measuring leg length inequality, especially in patients with lumbopelvic dysfunction. They compared the accuracy of measuring the pelvic crest height difference and leg length, using the PALM instrument, with the accuracy obtained with anteroposterior radiographs of the pelvis. The study showed that the PALM device is excellent for measuring pelvic crest height differences (ICC $=0.90$ and 0.92). However, these measurements were found to be less accurate compared with radiographic measurement of the leg length inequality ( $\mathrm{ICC}=0.76$ and 0.78 ). One explanation for these results is that measurements made with the pelvic leveling device was a direct evaluation of the degree of pelvic height discrepancy, but an indirect assessment of the height inequality of the femoral head.

Because there was a need to increase the accuracy and precision of the clinical mesurements' results, imaging methods were used for these evaluations.

For the comparison of imaging methods it was necessary to consider the reliability, accuracy, radiation, costs, the need for special equipment and the opportunity to view the entire leg. Currently the imaging methods are divided into three main categories: radiography, ultrasonography and magnetic resonance imaging.

According to the literature, there are six measurement methods that use the radiographic principle, such as: orthoroentogenography, scanography, teleoroentgenography, computed radiography, microdose digital radiography and computed tomography $[32,16]$.

The orthoroentogenography was designed to reduce the measurement errors resulting from enlargement, using three exposures centered on the hip, knee and ankle, processed on a single film. [11] The disadvantage of this method compared to a scanography is that it requires a longer cassette, which means higher costs, more storage space and special equipment.

The scanography can improve the measurement accuracy reducing the parallax errors. However, in patients with angular deformities, exposures centered on hip, knee and ankle joints do not allow an accurate assessment of the discrepancy.

Therefore the teleoroentgenography is a better choice, exposing the patient to less radiation. Moreover, when compared to the orthoroentogenography and scanography, the entire leg can be evaluated. Using this method, large discrepancies between the legs, where the level of the ankles and knees may differ substantially from one foot to another, can also be observed. Another advantage of this method is that it reduces errors that can occur within the other two methods, if the patient changes his position between exposures. However, several authors [11, 15, 75] noted the occurrence of a magnification error. The magnification error's magnitude depends on various factors, including length and circumference of limbs, distance from the X-ray source to the cassette and the divergence of X-ray beam. Cleveland and his collaborators [8] compared the measurements obtained with the teleoroentgenograph with the ones obtained using the ortoroentgenograph on a lot of 10 adult patients. Using the $10 \mathrm{~mm}$ value as a significant threshold of length difference, there was no difference reported between the two tests. Despite the magnification of about 5\%, the measurement accuracy of the inequality using anteroposterior radiographs is very similar to the one obtained with a scanogram, especially in the absence of a significant mechanical axis deviations [31].

The disadvantages of this technique are the high exposure to ionizing radiation, a significant increase of magnification $(6 \%)$, subjective errors in terms of reading teleoroentgenographys [11] and the need of special equipment, such as grids and filters [31].

Sabharwal and his colleagues [30] reported the reliability of their results, obtained by five observers with different degrees of experience, in the evaluation of 70 patients with leg inequality, using computed radiography on the base of scanographs and teleoroentgenographs. The reliability of the results obtained by all five observers was high for both scanography and teleoroentgenography. The mean absolute difference was 1.5 to $2.6 \mathrm{~mm}$ for scanography and 1.5 to $4.6 \mathrm{~mm}$ for teleoroentgenography. The authors recommend the use of teleoroentgenography, because although the reliability of this tehnique was as good as the one obtained by scanography it allowed a more comprehensive examination of the lower extremity.

The microdose digital radiography is another form of computer-assisted imaging solution, which substantially reduces the patient radiation exposure compared with conventional radiographic techniques [2].

In a study on a group of 25 children, who had leg length inequalitys, Altongy et al. [2] found that the microdose digital radiography is more accurate than the orthoroentogenography.

A flying spot digital imaging device was designed by Wilson and collaborators [36] in order to measure the length and angles of the skeleton. This device exposes the patient to a radiation dose of less than $2 \mathrm{mrad}$, which is considerably smaller than the one used for CT scans 
(15-20mrad) or than the one used for scanography (200250mrad) [1]. Patients can be examined both upright and supine. A wide visual field makes it possible to view in a single picture a large part of the body, such as the entire length of the spine, or lower extremities. Algorithms are integrated into the CPU and thus make it easier to calculate both the lengths and angles of the skeleton.

The digital images obtained with the computer tomography (CT) were also used for measuring lower extremities discrepancies, with a sensitivity of less than 1 mm [3, 1, 14]. Porat and Fields [28] compared the accuracy of computer tomography with the one obtained when measuring the discrepancies with conventional orthoroentogenography. Similar accuracy was reported with both techniques, with a $66 \%$ reduction in radiation dose when the CT was used. These studies [35, 28] demonstrated that the CT technique is accurate, easily reproducible and that it exposes the patients to low doses of radiation whe used for measuring the legs' inequalities.

The ultrasound evaluation technique, although worse than the CT in evaluating lower limb inequality, proved to be a good enough method to determine discrepancies, without using ionizing radiation and having a standard deviation of measurement reproducibility of $1.6 \mathrm{~mm}$. [18] Terjesen and colleagues [34], have recommended in their study the ultrasound evaluation technique as an initial assessment tool for patients prone to lower extremities inequality. Other studies [9, 21, 18] had also reported a high measurement reliability using ultrasound compared to other clinical and imaging methods.

Although magnetic resonance imaging (MRI) is traditionally used for imaging soft tissue, it is also suited to assess bone abnormalities. In a recent study [23], Leitzes and colleagues have compared MRI with computer tomography (CT) and scanography in order to analyze the evaluation potential of leg inequality. The reliability of the results was very high (ICC, 0.99) although when compared to the actual femur length, the mean absolute difference was $0.52 \mathrm{~mm}$ for scanography, $0.68 \mathrm{~mm}$ for CT and $2.90 \mathrm{~mm}$ for MRI. The advantage is that MRI does not expose patients to ionizing radiation, but is more expensive and can be contraindicated in patients with certain implanted devices. [19]

The intraoperative methods are also used, mainly in total hip arthroplasty, where post-operative results may include lower limb inequalities [4, 22, 17]. The measurements between fixed landmarks around the hip joint, presented by Takigami and colleagues [33], involves inserting two bolts in the pelvis, which will serve as a reference for measurement. According to preoperative radiographs, the average level of legs inequality is between $14.2 \pm 9.3 \mathrm{~mm}$, shortening ranging from $31 \mathrm{~mm}$, respectively lengthening from $10 \mathrm{~mm}$ after surgery. The leg length discrepancy showed a significant improvement, with a postoperative average of $4.2 \pm 3.2$ $\mathrm{mm}$. Although this method is very accurate, it does not correspond with the trend of "as less invasive as possible interventions".
Acrylic templates are also used by the surgeon to predict the approximate changes, noting the relationship between various fixed bony landmarks. In order to equalize the legs, the surgeon can also measure the femoral resected bone, depending on which the implant will be chosen. The method was used on a study of 796 patients. At $94 \%$ of these patients, the femoral component was placed, with a length difference of up to $6 \mathrm{~mm}$, compared with the preoperative estimated one [25].

The length measurement system in orthopedics [7] [24] is presented in figures 1-3, where the numbers represent the following:
1: base plate
2: 360 degree rotating joint
3: double articulated joint
4: retaning pin
5: connecting rod $(\log )$
6: retaining pin
7: connecting rod (medium) - proximal part
8: connecting rod (medium) - distal part
9: connecting rod (short)
10: X-Y-Z touch probe
11: ceramic sphere

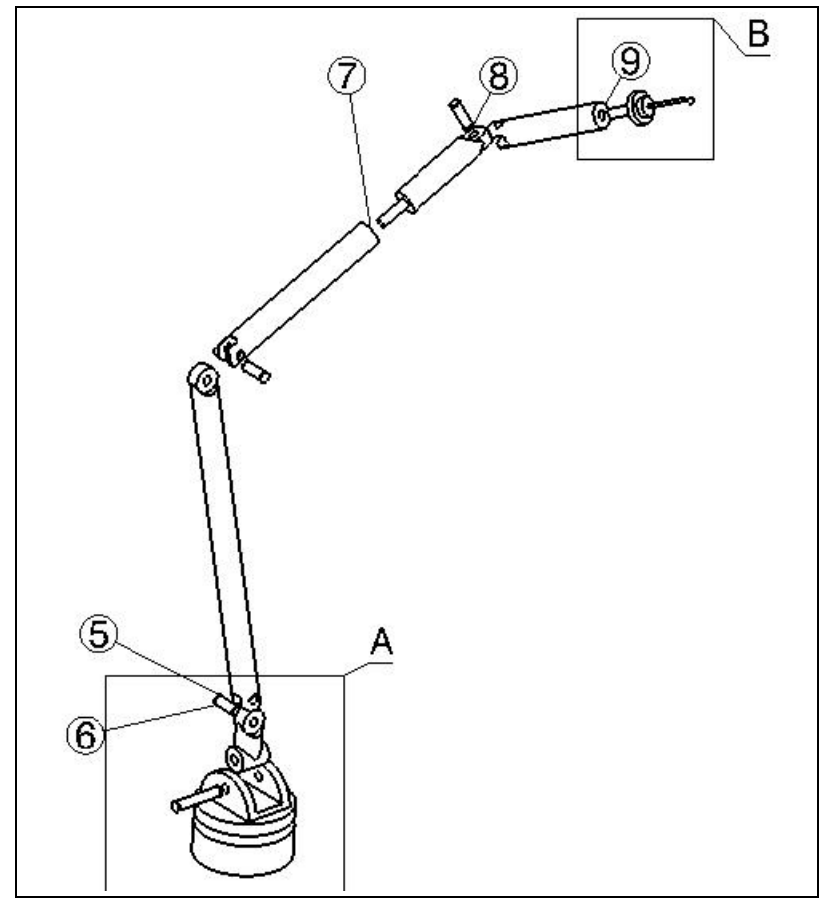

Fig. 1. The length measurement system in orthopedics

The length measurement system in orthopedics consists of four articulated rods (5), (7), (8), and (9) that allow the movement of the stylus measuring head (11) in a three dimesnional workspace. The stylus position is monitored continuously using a series of angular incremental transducers located inside the articulations, situated at each of the rods' extremities. The measuring system can also be placed on a stand with wheels, together with a command computer. In this configuration, the whole assembly can be moved and secured to the patient's bedside or operating table, in order to allow precise measurement of lengths in orthopedics. 


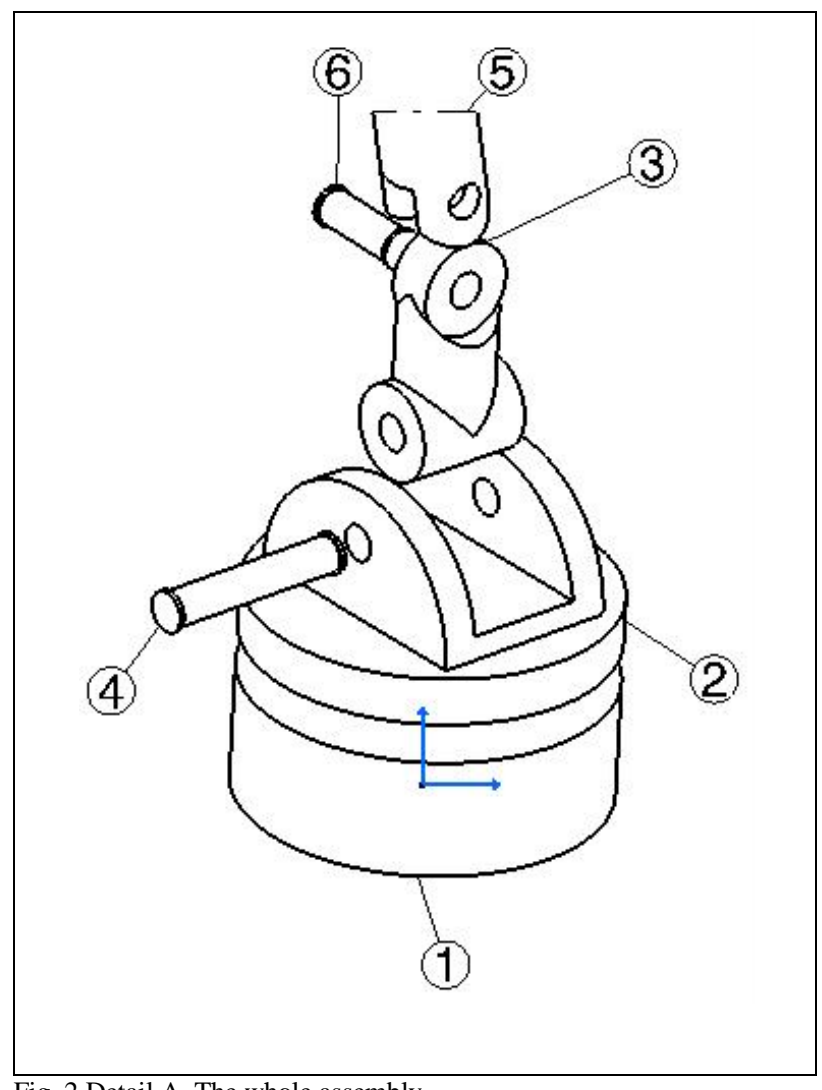

Fig. 2 Detail A. The whole assembly

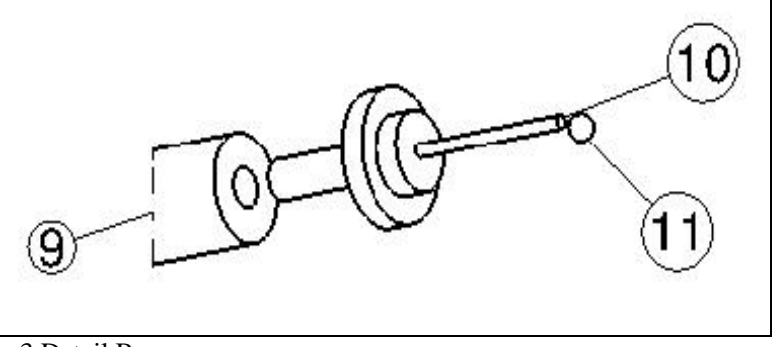

When the operator moves the probe and touches with its spherical head (11) a point of interest on the patient body, the transducers measure the angles of rotation of the system elements and the software determines the spatial coordinates of the sphere in relation to a predefined reference system. When the probe is moved to the second measuring point, its spatial coordinates are determined, and the distance between the two points is calculated, this representing the length of the measured bone segment.

This system has the advantage that it can measure more precise the lengths in orthopedics, both at bedside, and on the operating table, the results being then stored on the computer system. It can also determine the precise positions of the bone implant's holes, facilitating the operation of fixing them without having to use portable $\mathrm{X}$-ray machines, which will eliminate the risk of radiation exposure, both for the patient and the doctor. This increases the speed and convenience with which doctors can measure the lower limb's lengths. This device is not limited to leg measuring, but can be used for any bone segment in the human body. There are currently under investigation also other touch-trigger probes for this device and we are also trying to reduce the costs, in order for it to be more attractive to the medical community.

\section{CONCLUSION}

Based on the analysis of the orthopedic measuring methods, the authors have developed a table summarizing the data according to five criteria: accuracy, level of radiation to which the patient is exposed, price, availability and the learning curve. These criteria were ranked and after that to each of them was given a weight

Fig. 3 Detail B

\begin{tabular}{|c|c|c|c|c|c|c|c|c|c|}
\hline \multicolumn{3}{|c|}{ Measuring methods } & 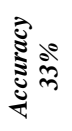 & 恋 & 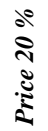 & 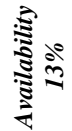 & 胥 & 气ัँ & 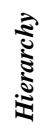 \\
\hline \multirow{3}{*}{ Clinical methods } & \multicolumn{2}{|c|}{ 1. Measurement method using a tape } & 1 & 5 & 5 & 5 & 5 & 3.68 & 5 \\
\hline & \multicolumn{2}{|r|}{ 2. Measurement method using wooden blocks } & 2 & 5 & 5 & 4 & 5 & 3.88 & 4 \\
\hline & \multicolumn{2}{|r|}{ 3. Measuring pelvic crest height difference } & 2 & 5 & 4 & 3 & 4 & 3.48 & 7 \\
\hline \multirow{8}{*}{ Imaging methods } & \multirow{6}{*}{ 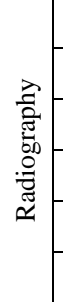 } & 1.Orthoroentgenography & 3 & 4 & 3 & 4 & 3 & 3.4 & 8 \\
\hline & & 2. Scanography & 3 & 4 & 3 & 4 & 3 & 3.4 & 8 \\
\hline & & 3. Teleoroentgenography & 3 & 3 & 3 & 4 & 3 & 3.13 & 10 \\
\hline & & 4. Computed radiography & 4 & 2 & 2 & 3 & 2 & 2.79 & 11 \\
\hline & & 5. Microdose digital radiography & 4 & 2 & 2 & 2 & 2 & 2.66 & 13 \\
\hline & & 6. Computed tomography & 5 & 2 & 1 & 2 & 2 & 2.79 & 12 \\
\hline & \multicolumn{2}{|c|}{ 7. Ultrasonography } & 4 & 5 & 2 & 3 & 1 & 3.53 & 6 \\
\hline & \multicolumn{2}{|c|}{ 8. Magnetic resonance imaging } & 4 & 5 & 1 & 1 & 2 & 3.14 & 9 \\
\hline \multirow{2}{*}{$\begin{array}{l}\text { Intraoperative } \\
\text { methods }\end{array}$} & \multicolumn{2}{|r|}{ 1. Measurement between fixed landmarks around the hip joint } & 5 & 5 & 4 & 3 & 3 & 4.4 & 2 \\
\hline & \multicolumn{2}{|r|}{ 2. Measurement of the resected femoral bone } & 4 & 5 & 4 & 2 & 3 & 3.94 & 3 \\
\hline \multicolumn{3}{|r|}{ 1. Length measurement system in orthopedics } & 5 & 5 & 4 & 4 & 4 & 4.6 & 1 \\
\hline
\end{tabular}

Tab. 1. A comparative analysis of orthopedic measuring methods 
and the sum of weights is 100 . Thus, as it also can be seen in Table 1, the learning curve accounts $7 \%$, availability $13 \%$, price $20 \%$, radiation level $27 \%$ and accuracy $33 \%$. Then, each method was given scores from 1 to 5 , where 1 means very poor and 5 very good. A weighted average was calculated, thus obtaining a score for each method.

Based on the scores, a hierarchy of methods could also be made. Table 1 shows the scores obtained for each method so that, for the clinical methods, the best score was obtained by the measuring method using wooden blocks (3.88), for the imaging methods, the best score was obtained by the ultrasound (3.53) and for the radiographic methods, the orthoroentogenography and the scanography are having the same score (3.4). The measurements between fixed landmarks around the hip joint is the best method of the intraoperative methods, with a score of 4.4 and the length measuring system in orthopedics proposed by the authors, achieved the highest score of 4.6 out of 5 .

Given these results, the authors propose the manufacture and implementation of the length measurement system in orthopedics, aiming at widespread use and thus improving the living standards and quality of life of the patients.

The analysis from figure 4, sets each measurement method side by side, creating an overview that can be helpful for the decision making of which method to use for the assessment of leg length discrepancy and then also to choose the appropriate treatment.

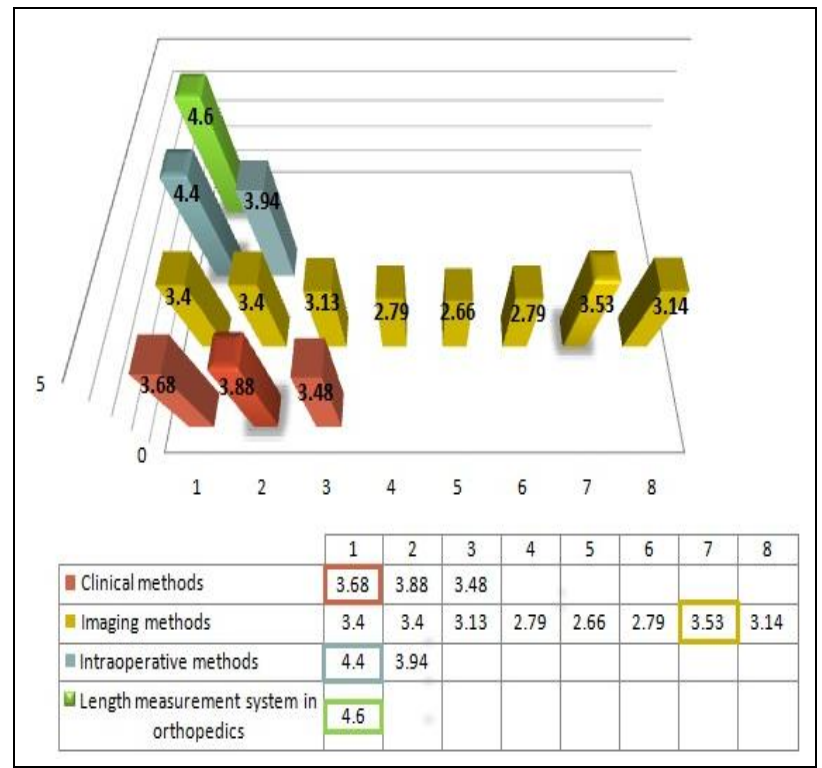

Fig. 4 Scoring the measuring methods in orthopedics

\section{REFERENCES}

[1] Aitken, G.F.; Flodmark, O.; Newman, D.E.; Kilcoyne, R.F.; Shuman, W.P. \& Mack, L.A. (1985). Leg length determination by $C T$ digital radiography. AJR Am J Roentgenol 1985; 144:613-615
[2] Altongy, J.F.; Harcke, H.T. \& Bowen, J.R. (1987). Measurement of leg length inequalities by Micro-Dose digital radiographs. J Pediatr Orthop. 1987 7:311-6

[3] Aron, A.; Weinstein, D.; Thickman, D. \& Eilert, R. (1992). Comparison of orthoroentgenography and computed tomography in the measurement of limb-length discrepancy. J Bone Joint Surg Am 1992; 74: 897-902

[4] Ball, B.S. (1996). A technique for comparison of leg lengths during total hip replacement. Am J Orthop. 1996; 25,(1): 61-2

[5] Beattie, P.; Isaacson, K.; Riddle, D.L. \& Rothstein, J.M (1990). Validity of derived measurements of leg-length differences obtained by use of a tape measure. Phys Ther 1990; 70(3):150-7

[6] Brêtas, D.A; Nogueira, J.V.F; Carneiro, M.V; Souza, R.A \& Simão, A.P. (2009): Analysis of intra-examiner reliability of the tape method measure to leg length discrepancy. Fit Perf J. 2009 Sep-Oct; 8(5):335-41

[7] Bucsan, C; Micu, C A.; Bogatu, L; Cristea, S \& Guica, R.I (2011).: Part I: On improving accuracy of length measurement in clinical orthopedic, U.P.B Sci. Bull. Series D, Vol 73 Iss. 2, pag 121-128, 2011

[8] Cleveland, R.H.; Kushner, D.C.; Ogden, M.C.; Herman, T.E.; Kermond, W. \& Correia, J.A (1988). Determination of leg length discrepance. A comparison of weight-bearing and supine imaging, Invest Radiol 1988, 23(4):301-4

[9] Defrin, R.; Ben, Benyamin S.; Aldubi, R.D. \& Pick, C.G. (2005): Conservative correction of leg-length discrepancies of $10 \mathrm{~mm}$ or less for the relief of chronic low back pain. Arch Phys Med Rehabil. 2005; 86:2075-2080

[10] Eichler, J.; (1972): Methodological errors in documenting leg length and leg length discrepancies., Der Orthopade. New York, NY, Springer-Verlag New York Inc, 1972, vol 1, pp 14-20 (translated from German)

[11] Green, W.T.; Wyatt, G.M. \& Anderson, M. (1946). Orthoroentgenography as a method of measuring the bones of the lower extremities. J Bone Joint Surg Am. 1946; 28:60-65

[12] Hagins, M; Brown, M; Cook, C; Gstalder, Karen K, Michael; K, Gene \& Strimbeck, K (1998). Intratester and intertester reliability of the palpation meter (PALM) in measuring pelvic position. J Manual Manip Ther. 1998; 6:130-136

[13] Hanada, E; Kirby, R. L; Mitchell, M \& Swuste, J.M. (2001). Measuring Leg-Length Discrepancy by the "Iliac Crest Palpation and Book Correction" Method: Reliability and Validity, Arch Phys Med Rehabil 2001; 82:938-42

[14] Helms, C.A. \& Mccarthy, S. (1984). CT scanograms for measuring leg length discrepancy. Radiology. 1984; 151:802

[15] Horsfield, D. \& Jones, SN. (1986). Assessment of inequality in length of the lower limb. Radiography. 1986; 52:223-227

[16] Huurman, W.W.; Jacobsen, F. S; Anderson, J.C. \& Chu, W-K (1987). Limb-Length Discrepancy Measured with Computerized Axial Tomographic Equipment, The Journal of Bone and Joint Surgery, Vol. 69-A, NO. 5. June 1987, pag 699-705

[17] Itokazu, M.; Masuda, K.; Ohno, T.; Itoh, Y.; Takatsu, T. \& Wenyi, Y. (1997). A simple method of intraoperative limp length measurement in total hip arthroplasty. Bull Hosp Jt Dis. 1997; 56(4): 204-5 
[18] Keppler, P.; Strecker, W.; Kinzl, L.; Simmnacher, M. \& Claes, L. (1999). Die sonographische Bestimmung der Beingeometrie. Orthopädie 1999; 28:1015-22

[19] Keppler, P.; Strecker, W. \& Kinzl, L. (1998). Die Analyse der Bein-Geometrie-Standard-Techniken und die Normalwerte. Chirurg 1998; 69:1141-52

[20] Krawiec, C.J.; Denegar, C.R.; Hertel, J.; Salvaterra, G.F. \& Buckley W.E. (2003). Static innominate asymmetry and leg length discrepancy in asymptomatic collegiate athletes, Manual Therapy 2003; 8(4): 207-213

[21] Krettek, C.; Koch, T.; Henzler, D.; Blauth, M. \& Hoffmann, R. (1996). A new procedure for determining leg length and leg length inequality using ultrasound. II: Comparison of ultrasound, teleradiography and 2 clinical procedures in 50 patients. Unfallchirurg. 1996; 99:43-51

[22] Küsswetter, W.; Hartwig, C.H. \& Willms, R.; (1995). Die intraoperative Bestimmung der Beinlänge beim alloplastischen Hüftgelenkersatz. Z Orthop. 1995; 133: 453-5

[23] Leitzes, A.H.; Potter. H.G.; Amaral, T.; Marx, R.G.; Lyman, S. \& Widman, R.F. (2005). Reliability and accuracy of MRI scanogram in the evaluation of limb length discrepancy. J Pediatr Orthop. 2005; 25:747-749

[24] Micu, C.A; Bucşan, C; Bogatu, L; Cristea, S (2011). Sistem de măsurare a lungimilor în ortopedie, Buletinul Oficial De Proprietate Industriala, Sectiunea Brevete de Inventie, RO-BOPI 1/2011, din 28.01.2011, pag 12

[25] O’brien, S.; Engela, D.W.; Trainor, P. \& Beverland, D.E. (1996). Assesing the accuracy of femoral component placement in custom cemented hip replacement. Orthop Nurs. 1996; 15(4): 47-53

[26] Papadopoulos, A.X.; Tsota, I. \& Megas, P. (2002). Methods for estimating leg length discrepancy: Emphasis to the planning and performance of total hip arthroplasty, Journal of Hellenic Association of Orthopaedic Surgery and Traumatology. 2002; 53(4)

[27] Petrone, M.R.; Guinn, J; Reddin, A; Sutlive, T.G.; Flynn, T.W. \& Garber, Matthew P (2003). The Accuracy of the Palpation Meter (PALM) for Measuring Pelvic Crest Height Difference and Leg Length Discrepancy, Journal of Orthopaedic \& Sports Physical Therapy, 2003; 33:319325

[28] Porat, S. \& Fields, S. (1989). Limb length discrepancy determined by computerized tomography and radiography . Harefuah. 1989; 116:515-516

[29] Reid, D.C. \& Smith, B. (1984). Leg length inequality: a review of etiology and management. Physio Can 1984; 36: 177-82

[30] Sabharwal, S.; Zhao, C.; Mckeon, J.; Melaghari, T.; Blacksin, M. \& Wenekor, C. (2007). Reliability analysis for radiographic measurement of limb length discrepancy: full-length standing anteroposterior radiograph versus scanogram. J Pediatric Orthop. 2007; 27:46-50

[31] Sabharwal, S; Zhao, C; Mckeon, J J.; Mcclemens, E; Edgar, M \& Behrens, F (2006). Computed Radiographic Measurement of Limb-Length Discrepancy. Full-Length Standing Anteroposterior Radiograph Compared With Scanogram. The Journal Of Bone \& Joint Surgery 2006; 88-A(10): 2243-2251

[32] Sabharwal, S \& Kumar, A (2008). Methods for Assessing Leg Length Discrepancy, Clin Orthop Relat Res (2008) 466:2910-2922
[33] Takigami, I; Itokazu, M; Itoh, Y; Matsumoto, K; Yamamoto, T \& Shimizu, K (2008). Limb-Length Measurement in Total Hip Arthroplasty Using a Calipers Dual Pin Retractor; Bulletin of the NYU Hospital for Joint Diseases 2008; 66(2):107-10

[34] Terjesen, T; Benum, P; Rossvoll, I; Svenningsen, S; Floystad I; Anne, E \& Nordbo, T (1991). Leg-length discrepancy measured by ultrasonography, Acta Orthop Scand 1991; 62(2): 121-124

[35] Temme, J.B.; Chu, W.K. \& Anderson, J.C. (1987). CT scanograms compared with conventional orthoroentgenograms in long bone measurement. Radiol Technol. 1987; 59:65-68

[36] Wilson, A J. \& Ramsby, G R. (1987). Skeletal Measurements Using a Flying Spot Digital Imaging Device, American Roentgen Ray Society 1987; 149:339343 